\title{
KONTRIBUSI YOUNG INTERFAITH PEACEMAKER COMMUNITY (YIPC) DALAM MENYEBARKAN NARASI KONTRA RADIKALISME
}

\author{
M. Royyan Nafis Fathul Wahab \\ Universitas Islam Negeri Sunan Ampel Surabaya \\ m.royyannafis@gmail.com
}

Received: 06-04-2020

Revised: 16-06-2020

Accepted: 26-06-2020

\section{Contribution Of Young Interfaith Peacemaker Community (YIPC) in Spreading The Narrative Contrads of Radicalism}

\begin{abstract}
This research departs from the problem of the ideology of radicalism that developed in Indonesia. The ideology of radicalism in its spread through social media targets many young people as their targets. This is evidenced by the presence of several young people who participated in becoming sympathizers of terrorism and even carried out acts of terror on the basis of religion. The subject of this research is the Young Interfaith Peacemaker Community (YIPC) organization and the object is the YIPC program that can be used to spread counter radicalism narratives. The objectives of this research are: exploring the YIPC program in spreading counter radicalism narratives, analyzing the manifestations of the YIPC Program in spreading counter radicalism narratives, and exploring the Role of YIPC in spreading counter radicalism narratives. This research is a qualitative research analyzed descriptively. Data was collected through field observations, interviews, and documents relating to the YIPC program as primary sources and books, journals, magazines, and internet information as secondary sources. The results of this study indicate that YIPC bas a role as a forum and interfaith youth facilitator who concentrates on the concept of peace education and interfaith dialogue based on the scriptures to build peace through peaceful cadres by spreading fourteen basic values of peace aimed at reducing radicalism and ideological intolerance.
\end{abstract}

Keywords: Counter-Radicalism, Intolerance, Narrative, Role

\begin{abstract}
Abstrak
Penelitian ini berangkat dari masalah ideologi radikalisme yang berkembang di Indonesia. Ideologi radikalisme dalam penyebarannya melalui media sosial menargetkan banyak pemuda sebagai sasarannya. Ini dibuktikan dengan hadirnya beberapa anak muda yang ikut menjadi simpatisan terorisme dan bahkan melakukan aksi teror atas dasar agama. Subjek penelitian ini adalah organisasi Young Interfaith Peacemaker Community (YIPC) dan objeknya adalah program YIPC yang dapat digunakan untuk menyebarkan narasi kontra radikalisme. Tujuan dari penelitian ini adalah: mengeksplorasi program YIPC dalam menyebarkan narasi kontra radikalisme, menganalisis manifestasi Program YIPC dalam menyebarkan narasi kontra radikalisme, dan mengeksplorasi Peran YIPC dalam menyebarkan narasi kontra radikalisme. Penelitian ini adalah penelitian kualitatif yang dianalisa secara deskriptif. Data dikumpulkan melalui observasi lapangan, wawancara, dan dokumen yang berkaitan dengan program YIPC sebagai sumber primer serta buku, jurnal, majalah, dan informasi internet sebagai sumber sekunder. Hasil penelitian ini menunjukkan bahwa YIPC
\end{abstract}


memiliki peran sebagai wadah dan fasilitator pemuda antaragama yang berkonsentrasi pada konsep pendidikan perdamaian dan dialog antaragama berdasarkan kitab suci untuk membangun perdamaian melalui kader damai dengan menyebarkan empat belas nilai dasar perdamaian yang bertujuan untuk mengurangi radikalisme dan intoleransi ideologi.

Kata Kunci : Intoleransi, kontra-radikalisme, Narasi, Peran,

\section{PENDAHULUAN}

Radikalisme agama telah menjadi perdebatan hangat di kalangan sarjana muslim bahkan menjadi isu nasional problematika pemuda ${ }^{1}$. Misalnya gerakan khilafah yang dilakukan oleh Hizbut Tahrir (HTI) Indonesia yang mencari kader militan dari mayoritas pemuda ${ }^{2}$ yang pada akhirnya HTI dibubarkan oleh pemerintah melalui putusan PTUN karena terbukti sebagai organisasi yang mengusung sistem khilafah dan ingin menggulingkan sistem pemerintahan yang sah dan telah disepakati oleh setiap elemen bangsa ${ }^{3}$. Gerakan radikal yang mentargetkan pemuda menjadikan Young Interfaith Peacemaker Community (YIPC) memunculkan konsep peace values ${ }^{4}$ sebagai narasi kontra radikal agama yang mentargetkan pemuda sebagai objeknya. Isu penciptaan perdamaian berdasarkan konsep program YIPC bisa menjadi alternatif untuk menarasikan kontra radikalisme kepada pemuda yang terpapar ideologi radikal. Puncaknya, peace values bisa disebarkan secara masif untuk menjadi narasi kontra radikal.

Dalam konteks ke-Indonesiaan, narasi radikal disebarkan secara masif melalui jejaring sosial seperti Facebook, Instagram, dan Twitter. ${ }^{5}$ Hal ini mengakibatkan pemuda sebagai

1 Muzayyin Ahyar, "Membaca Gerakan Islam Radikal Dan Deradikalisasi Gerakan Islam," Walisongo: Jurnal Penelitian Sosial Keagamaan 23, no. 1 (15 Juni 2015): 1-26, https://doi.org/10.21580/ws.23.1.220; Syamsul Arifin, "Membendung Arus Radikalisasi di Indonesia," Islamica: Jurnal Studi Keislaman 8, no. 2 (1 Maret 2014): 392-420, https://doi.org/10.15642/islamica.2014.8.2.392-420; A. Jainuri, Radikalisme dan terorisme: akar ideologi dan tuntutan aksi (Intrans Publishing, 2016); Khamami Zada, "Radikalisme Di Jantung Pendidikan Islam," EDUKASI: Jurnal Penelitian Pendidikan Agama Dan Keagamaan 7, no. 4 (15 Mei 2017), https://doi.org/10.32729/edukasi.v7i4.256.

2 Penyebaran Hizbut Tahrir di lingkungan mahasiswa dimulai dengan hadirnya Aburrahman alBaghdadi, seorang aktivis HTI yang berasal dari libanon ke Kampus IPB. Lihat Azman Azman, "Gerakan Dan Pemikiran Hizbut Tahrir Indonesia," Al Daulah : Jurnal Hukum Pidana Dan Ketatanegaraan 7, no. 1 (16 Juli 2018): 99-113, https://doi.org/10.24252/ad.v7i1.5329.

${ }^{3}$ HTI dibubarkan dengan bermodalkan Perppu No. 2 Tahun 2017 tentang organisasi kemasyarakatan. Lihat Abd Qohar dan Kiki Muhamad Hakiki, "Eksistensi Gerakan Idiologi Transnasional HTI Sebelum dan Pasca Pembubaran," KALAM 11, no. 2 (31 Desember 2017): 365-96, https://doi.org/10.24042/klm.v11i2.1403.

${ }^{4}$ Peace values yang dikemukan oleh YIPC berakar pada tiga aspek yakni aspek ketuhanan, aspek kemanusiaan, dan aspek alam. YIPC, Dokumen Kompilasi Modul Pendidikan Perdamaian YIPC Indonesia, 2018, 3.

${ }^{5}$ Nafi' Muthohirin, "Radikalisme Islam dan Pergerakannya di Media Sosial," Jurnal Ilmu-Ilmu Keislaman Afkaruna 11, no. 2 (Desember 2015): 250-251, https://doi.org/10.18196/aiijis.2015.0050.240-259. 
konsumen terbesar Internet $^{6}$ terancam propaganda narasi-narasi radikal yang mengancam keutuhan bangsa. Fenomena yang terjadi seperti ini menegaskan bahwa YIPC mengambil bagian dalam membuat narasi kontra radikal yang berbasis pada peace values.

YIPC telah mengkader 2.227 aktivis perdamaian dalam kurun waktu enam tahun (2012-2018). Dalam proses pengkaderan, tidak hanya mencari aktivis pemuda yang berkonsentrasi kepada isu perdamaian, namun juga berhasil merubah mindset radikal pemuda menjadi non-radikal setelah mengikuti beberapa program yang diadakan oleh YIPC. ${ }^{7}$

Program YIPC mengakomodir narasi kontra radikal dari dua agama yakni Islam dan Kristen. Dalam riset yang dilakukan oleh Andreas Jonathan, Paulus Widjaja, and Fatimah Husein mengeksplorasi bahwa YIPC merupakan sarana pembinaan ekslusivitas agama dan politik. ${ }^{8}$ Dalam YIPC mereka menegaskan bahwa program YIPC dapat menekan dan menjadi salah satu model counter radikalisme dalam agama maupun ekslusivitas politik di Indonesia. Dalam proses observasi, mereka melihat bahwa pemuda Muslim dan Kristiani duduk dalam satu forum dan saling melemparkan prasangka yang selama ini disimpan untuk saling memberikan klarifikasi. Tujuan dari forum tersebut adalah untuk membangun persahabatan antar kedua agama dan menghilangkan prasangka antar satu sama lain yang merupakan sumber konflik. Diakhir penelitian, mereka memiliki kesimpulan bahwa konsep peace values yang digagas oleh YIPC memungkinkan kedua agama memiliki toleransi beragama antar satu sama lain melalui dialog dalam berbagai aspek kehidupan.

Artikel ini akan mengeksplorasi program YIPC dalam menyuarakan narasi kontra radikal berbasis peace values dalam setiap program-programnya guna menyebarkan narasi kontra radikalisme dalam domain reedukasi ${ }^{9}$ menggunakan teori peran sebagai sudut pandang. Dalam hal ini akan diungkap bagaimana peran serta kontribusi YIPC dalam membangun narasi kontra radikalisme. Selain itu, penulis juga mengulas bagaimana fondasi Islam dan Kristen berbasis kitab suci dalam membangun narasi kontra-radikal dalam program YIPC.

${ }^{6}$ Berdasarkan data dari Asosiasi Penyedia Jasa Internet Indonesia (APJII) mengemukakan hasil survey bahwa dari 143,26 juta pengguna internet sebesar 49,52\% merupakan generasi milenial dengan rentan usia 19-34 tahun. Lihat Asosiasi Penyedia Jasa Internet Indonesia, "Hasil Survey Penetrasi dan Perilaku Pengguna Internet Indonesia Tahun 2017," Diakses 11 Juni 2020, https:/ /apjii.or.id/survei.

$$
\text { 7Anisa, “Testimoni”, YIPC Newsletter Peace News, (Februari 2018): 23, }
$$
http://peacenews.yipci.org/peacenews-februari-2018-eksklusivisme-perlukah/.

${ }^{8}$ Andreas Jonathan, Paulus Widjaja, and Fatimah Husein, "Fostering Religious Exclusivism and Political Pluralism In Indonesia Through Interefaith-Based Student Community," KnE Social Sciences 3, no. 5 (Mei 2018): 68, https://doi.org/10.18502/kss.v3i5.2325.

${ }^{9}$ Reedukasi adalah salah satu upaya Badan Nasional Penanggulangan Terorisme (BNPT) dalam melakukan deradikalisasi kepada narapidana teroris. Lihat UU No. 52018. 


\section{METODE PENELITIAN}

Penelitian ini merupakan penelitian lapangan (field research). Data diambil dari lapangan baik berupa dokumen, observasi maupun wawancara, ${ }^{10}$ sehingga teknik pengumpulan datanya dilakukan melalui pengumpulan sumber-sumber primer maupun sekunder. Data penelitian ini menggunakan data kualitatif yang dinyatakan dalam bentuk kata atau kalimat. ${ }^{11}$ Ada dua jenis data yaitu data primer dan sekunder. Data primer dalam penelitian ini adalah dokumen, hasil observasi dan wawacara mengenai Young Interfaith Peacemaker Community. Sedangkan sumber sekundernya adalah buku-buku sosiologi, radikalisme dan buku-buku lain yang relevan dengan tema yang dikaji.

Untuk menganalisis data, penelitian ini menggunakan metode deskriptif-analisis yang berarti dilakukan dengan cara menyajikan deskripsi sebagaimana adanya, kemudian dianalisa lebih mendalam. ${ }^{12}$ Usaha pemberian deskripsi atas fakta tidak sekedar diuraikan, tetapi lebih dari itu, yakni fakta dipilih-pilih menurut klasifikasinya, diberi intepretasi, dan refleksi. ${ }^{13}$ Karena objek kajian penelitian ini adalah program YIPC dalam menarasikan kontra radikalisme maka yang diperoleh dari hasil obeservasi, dan wawancara dari YIPC maka teori yang relevan adalah teori peran. Teori peran digunakan untuk menganalisa hasil observasi dan wawancara dengan outputnya adalah mengelaborasi peran yang sedang dimainkan oleh YIPC dalam menyebarkan narasi kontra radikalisme agama. Hal ini yang dapat dilihat dari program YIPC yang telah diejawantahkan. Di dalam teori peran hal ini disebut sebagai skrip yang harus dijalankan oleh masing-masing aktor. ${ }^{14}$

\section{HASIL DAN PEMBAHASAN}

\section{Sejarah Perkembangan YIPC}

Sejarah YIPC terbentuk yakni dimulai dengan gerakan dua mahasiswa ICRS (Indonesian Consortium for Religious Studies) yang bernama Andreas Jonathan dan Ayi Yunus Rusyana untuk mengadakan Young Peacemaker Training di Gedung Pascasarjana UGM Yogyakarta pada tanggal 9-12 Juli 2012. ICRS adalah sebuah Ph.D. Program Internasional (S-3) di bidang studi antar agama yang bekerja sama dengan Universitas Gajah Mada, Universitas Islam Negeri Sunan Kalijaga dan Universitas Kristen Duta Wacana.

\footnotetext{
${ }^{10}$ Hadari Nawawi, Metodologi penelitian Bidang Sosial (Yogyakarta: Gajah Mada Universy press, 2001), 95.

${ }^{11}$ Amirul Hadi dan H. Haryono, Metodologi Penelitian Pendidikan (Bandung: Pustaka Setia. 1998), 126.

${ }^{12}$ Siswantoro, Metode Penelitian Sastra: Analisis Psikologis, (Surakarta: Sebelas Maret University Press, 2004), 49. 13Ibid., 50.

${ }^{14} \mathrm{~B}$ J Biddle, "Recent Developments in Role Theory," t.t., 68. http://doi.org/10.1146/annurev.so.12.080186.000435.
} 
Pelatihan ini dihadiri oleh 25 mahasiswa sarjana Muslim dan Kristen dari berbagai kampus di Yogyakarta dan menjadi cikal bakal Komunitas Perdamaian Pemuda Jogja (YPC). Dalam pelatihan ini, 12 Nilai Perdamaian dari Peace Generation (sebuah LSM yang berada di Bandung) dipelajari. Sebagai tindak lanjut dari pelatihan ini, mulai bulan September 2012 diadakan pertemuan rutin para anggota YPC Jogja diadakan dengan mengadakan dialog antaragama, kajian kitab suci dan persiapan untuk mengadakan Student Interfaith Peace Camp pada bulan November 2012. Peace Camp pertama kali diadakan di Pakem-Yogyakarta dan dihadiri oleh 30 mahasiswa dari Yogyakarta maupun luar Yogyakarta (Palembang, Bandung, Kebumen, Solo, Surabaya dan Madura) dengan tema "Building Peace Generation Through Young Peacemakers". Tema ini kemudian menjadi moto atau pernyataan misi YPC Indonesia. ${ }^{15}$

Karena semakin beragamnya wilayah yang berpartisipasi, setelah Peace Camp, nama YPC Jogja diubah menjadi YPC Indonesia (YPCI). Pada tahun 2013 bulan Maret-Mei, YPCI mengadakan tiga Student Interfaith Peace Camp di Medan (untuk Sumatra), di Trawas (untuk Jawa Timur), dan di Kaliurang (untuk Jogja dan Jawa Tengah). Rata-rata peserta Peace Camp adalah 30 siswa Muslim dan Kristen. Sejak itu, YPCI telah ada di 3 kota: Jogja, Medan dan Surabaya dengan mengadakan Dialog Reguler setiap minggu.

Pada bulan Juli 2013, untuk memperingati satu tahun usia YPCI, Young Interfaith Peacemaker National Conference diadakan dan dihadiri oleh hampir 50 mahasiswa dari berbagai kota. Konferensi yang diadakan di Magelang ini mengangkat tema "Loving God - Loving Others, Let's Do Something About I $t^{\prime}$ ' dengan mengambil landasan diskusi yang berdasarkan pada dokumen "A Common Word Between You and Us". Pada akhir Konferensi Nasional ini, nama YPCI disempurnakan menjadi Young Interfaith Peacemaker Community (YIPC) Indonesia dengan 3 cabang yakni YIPC Medan, YIPC Joglosemar dan YIPC Jawa Timur.

Pada paruh kedua 2013, YIPC melanjutkan dengan Peace Camp di Medan, Bandung (Jawa Barat), Jogja dan Jawa Timur pada tanggal 15-17 November 2013. Peace Camp berlanjut setiap tahun dua kali (pada bulan April dan November). Pada tahun 2014, YIPC mengadakan 3 acara nasional yakni: National Training For Facilitator (TFF), National Student Interfeith Peace Camp dan Young Interfaith Peacemaker National Conference yang kedua. ${ }^{16}$

Pada tahun 2015, YIPC mulai bekerja secara internasional melalui Ambasador WIHW (World Harmony Interfaith Week) ${ }^{17}$ di Malaysia dan Singapura pada tanggal 2-7 Februari 2015.

\footnotetext{
${ }^{15}$ Booklet YIPC Seri 1, Mengenal Young Interfaith Peacemaker Community Indonesia (YIPC), 2.

16Ibid., 2.

17Pekan Antaragama Antaragama Sedunia adalah resolusi PBB untuk satu minggu di seluruh dunia
} harmoni antaragama yang diusulkan pada 2010 oleh Raja Abdullah II dan Pangeran Ghazi bin Muhammad dari 
Pada April 2015, TFF kedua diadakan. Dan YIPNC (National Conference) ketiga diadakan pada tanggal 1-8 Agustus 2015 dengan tema: "Firman-Mu Adalah Terang untuk Hidupku". ${ }^{18}$ Dengan adanya berbagai kegiatan yang telah dipromosikan oleh YIPC, diharapkan bahwa di masa mendatang YIPC akan dibentuk di kota-kota dan di negara-negara lain sehingga kader peacemaker yang lebih luas dan militan akan muncul.

Hingga saat ini, di setiap semester YIPC selalu mengadakan Peace Camp di berbagai daerah seperti Bandung, Yogyakarta, Surabaya, Malang, Medan, dan Jakarta. Semangat yang dibangun dalam komunitas ini adalah untuk membangun perdamaian dengan berpegang teguh pada kitab-kitab suci, terutama Alquran, Taurat dan Injil. Sehingga nilai-nilai perdamaian yang diajarkan didasarkan pada kitab suci. Selain itu, YIPC juga mendukung gerakan A Common Word (ACW), sebuah dokumen yang berisi dua hal fundamental antara Islam dan Kristen, yaitu mencintai Tuhan dan mencintai sesama. Kedua dasar ini adalah landasan gerakan YIPC. ${ }^{19}$

Fokus kegiatan YIPC adalah pendidikan perdamaian untuk mahasiswa dan dialog antaragama untuk pemuda. Dialog antaragama ini dilakukan untuk memutus rantai prasangka dan kebencian antara kedua agama dan untuk membangun kehidupan yang harmonis antara kedua agama (Islam dan Kristen). Saat ini, selain terus berkolaborasi dengan ICRS, Peace Generation dan Campus Peace Movement, YIPC juga memperluas kolaborasi dengan bergabung di beberapa lembaga internasional, seperti Masterpeace dan United Network of Young (UNOY) Peace Builders. $^{20}$

\section{Dasar dan Tujuan Berdirinya YIPC}

Berbicara mengenai dasar dan tujuan pembentukan YIPC adalah berbicara tentang visi dan misi organisasi. Visi YIPC adalah generasi damai berdasarkan cinta kepada Tuhan dan orang lain. Sedangkan misi YIPC yakni: Pertama, untuk melakukan dialog antaragama yang terbuka, jujur, dan mendalam secara teratur. Kedua, menggerakkan pemuda dan masyarakat untuk hidup damai dan saling mencintai. Ketiga, terlibat dalam proses transformasi bangsa dan dunia dalam mewujudkan perdamaian global. Dari pemaparan visi dan misi YIPC, dapat ditarik pemahaman bahwa kehadiran YIPC didasarkan pada cinta kasih kepada Tuhan dan sesama yang bertujuan untuk membentuk generasi muda yang damai sebagai sarana penyebaran perdamaian dan meredakan konflik terutama atas nama agama. Konsep tujuan

Yordania. Pekan Harmoni Antaragama Sedunia jatuh pada minggu pertama bulan Februari setiap tahun dan bertujuan untuk mempromosikan keharmonisan antara semua orang tanpa memandang keyakinan mereka.

${ }^{18}$ Booklet YIPC Seri 1, Mengenal Young Interfaith Peacemaker Community Indonesia (YIPC), 2.

${ }^{19}$ Booklet YIPC Seri 1, Mengenal Young Interfaith Peacemaker Community Indonesia (YIPC), 3.

${ }^{20}$ Ibid., 3. 
pembentukan generasi damai melalui beberapa gerakan YIPC seperti mengadakan dialog antaragama, terutama tema-tema sensitive antar agama sehingga dapat ditemukan solusi bersama, memobilisasi pemuda untuk aktif dalam menyebarkan perdamaian baik di jalan maupun melalui tulisan, bekerja sama dengan beberapa birokrasi negara untuk melakukan transformasi guna mencapai perdamaian global. $^{21}$

\section{Nilai Dasar Perdamaian YIPC}

Konsep nilai perdamaian sebagai dasar narasi kontra radikalisme agama adalah inti dari gerakan YIPC untuk menyebarkan perdamaian. Status organisasi yang menyebut dirinya sebagai forum lintas agama ini mengambil konsep perdamaian dari kitab suci kedua agama, yaitu Islam dan Kristen dengan tujuan untuk menjadi pondasi saling menghormati dan saling memahami antar satu sama lain. Ketika disebutkan dalam dua kitab suci tersebut, konsep perdamaian dalam Alquran dan Injil, Taurat tidak memiliki perbedaan secara signifikan. Di bawah ini adalah konsep nilai perdamaian sebagai referensi bagi YIPC dalam menjalankan gerakannya sebagai generasi damai dalam menyebarkan narasi kontra radikalisme agama.

\section{Menerima Diri}

Dalam konsep menerima diri, yang dimaksudkan adalah menerima diri sendiri atas segala kekurangan dan kelebihan yang dimiliki individu. Nilai perdamaian ini mengambil dasar dari Alquran yakni surat al-Tin ayat 4

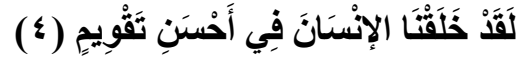
Sesungguhnya Kami telah menciptakan manusia dalam bentuk yang sebaik-baiknya. ${ }^{22}$

Selain mengambil dasar dari Alquran, menerima diri dalam konteks perdamaian Young Interfaith Peacemaker Community juga mengambil dasar dari Taurat (perjanjian lama) yakni dalam surat Yesaya ayat 6b-7

Bawalah anak-anak lelaki-Ku dari jauh dan anak-anak perempuan-Ku dari ujung bumi, yaitu semua orang yang disebutkan dengan nama-Ku, yang Kuciptakan untuk Kemuliaan-Ku, yang Kubentuk, dan yang Kujadikan. ${ }^{23}$

Dari dua sumber kitab suci di atas, ada sejumlah hal yang dapat dipahami dalam konteks menerima diri perspektif YIPC. Pertama, manusia adalah ciptaan Tuhan yang luar biasa, ini adalah identitas manusia yang pertama dan terpenting. Kedua, manusia

\footnotetext{
${ }^{21}$ Anggaran Dasar dan Anggaran Rumah Tangga Young Interfaith Peacemaker Community, 2.

22Alquran, 95:4

${ }^{23}$ Injil, Yesaya 43: 6b-7.
} 
harus percaya bahwa Tuhan tidak pernah salah dalam menciptakan siapa pun. Ketiga, manusia harus bisa mengetahui kekuatan dan kelemahan yang ada dalam dirinya. Keempat, manusia harus dapat melihat dengan baik dan seimbang dalam dirinya untuk menghindari sifat sombong dan tidak percaya diri. Kelima, pengalaman suka dan duka dalam hidup akan mempengaruhi bagaimana seseorang menerima diri mereka sendiri. Dengan demikian dapat disimpulkan bahwa, jika seseorang ingin berdamai dengan sesamanya yang dalam hal ini adalah konteks kontra-radikal dalam diri, sudah seharusnya seseorang harus dapat berdamai dengan diri mereka sendiri terlebih dahulu. ${ }^{24}$

\section{Mengatasi Prasangka}

Konsep yang selanjutnya dalam nilai dasar perdamaian adalah mengatasi dan menjauhi prasangka. Dalam konsep ini, individu dituntut untuk menghindari prasangka negatif kepada orang lain karena prasangka merupakan penghakiman secara sepihak yang belum tentu kebenarannya. Dalam Alquran dijelaskan dalam surat al-Hujurat ayat 12 .

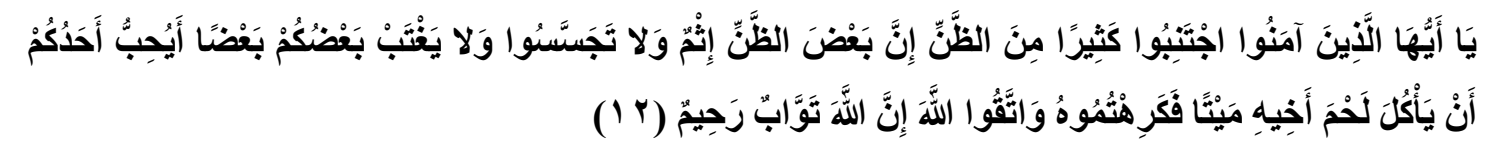

Hai orang-orang yang beriman, jauhilah kebanyakan purba-sangka (kecurigaan), karena sebagian dari purbasangka itu dosa. dan janganlah mencari-cari keburukan orang dan janganlah menggunjingkan satu sama lain. Adakah seorang diantara kamu yang suka memakan daging saudaranya yang sudah mati? Maka tentulah kamu merasa jijik kepadanya. dan bertakwalah kepada Allah. Sesungguhnya Allah Maha Penerima taubat lagi Maha Penyayang. ${ }^{25}$

Dalam Kitab Taurat dan Injil juga dijelaskan mengenai prasangka yakni dalam surat Zabur 17: 2a dan surat Matius 7:1

Dari pada-Mulah kiranya datang penghakiman."26

Jangan kamu menghakimi, supaya kamu tidak dihakimi."27

Dari penjelasan kedua kitab suci diatas tentang mengatasi dan menjauhi prasangka dapat diambil beberapa poin. Pertama, Berpikir negatif dan menghakimi orang lain tanpa berdasarkan fakta adalah bentuk sikap yang tidak bertanggung jawab dan merupakan perbuatan dosa. Kedua, Konsep diri, keinginan berkompetisi, dan konformitas adalah faktor-faktor yang mempengaruhi prasangka dan stereotip. Ketiga, Prasangka jika tidak

\footnotetext{
${ }^{24}$ YIPC, Dokumen Kompilasi, 4-10.

${ }^{25}$ Alquran, 49:12

${ }^{26}$ Injil, Zabur 17:2a.

${ }^{27}$ Injil, Matius 7:1.
} 
diselesaikan akan menghasilkan stereotip yang berujung pada penghakiman dalam wujud perkataan dan tindakan. Individu yang memiliki prasangka buruk terhadap sesamanya dapat diketahui dari beberapa indikator seperti sering menghindar bila bertemu, anti terhadap sosial, melakukan tindak kekerasan terhadap apa yang dipahaminya salah, serta merendahkan tingkat kesalehan yang dimiliki orang lain. Adapun cara mengatasi prasangka seperti menjalin interaksi dengan pribadi atau kelompok yang diprasangkai, klarifikasi langsung, menghargai keunikan pribadi atau kelompok dan melakukan kerja nyata. Dari konsep mengatasi prasangka dapat diambil kesimpulan yakni seorang individu harus menilai seseorang berdasarkan fakta dirinya, bukan berdasarkan anggapan umum terhadap kelompoknya ataupun sebaliknya. ${ }^{28}$

\section{Merayakan Keberagaman}

Konsep yang ketiga dalam nilai dasar perdamaian adalah merayakan keberagaman. Sudah menjadi hukum alam bahsawannya semua makhluk yang ada dibumi diciptakan secara beragam. Dalam konteks sains, walaupun seseorang dilahirkan secara kembar identik, ada perbedaan yang signifikan pada sidik jarinya. Oleh karena itu, tidak ada makhluk di dunia yang diciptakan seratus persen sama. Itulah mengapa yang harus dimengerti oleh sesama manusia bahwa sudah seyogyanya saling menghargai atas keberagaman yang ada. Dalam Alquran keberagaman dijelaskan dalam surat al-Hujurat ayat 13 .

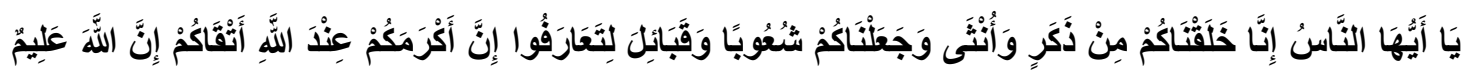 خَبِيرٌ (1) (1)}

Hai manusia, Sesungguhnya Kami menciptakan kamu dari seorang laki-laki dan seorang perempuan dan menjadikan kamu berbangsa - bangsa dan bersuku-suku supaya kamu saling kenal-mengenal. Sesungguhnya orang yang paling mulia diantara kamu disisi Allah ialah orang yang paling taqwa diantara kamu. Sesungguhnya Allah Maha mengetahui lagi Maha Mengenal. ${ }^{29}$

Dijelaskan juga dalam Kitab Taurat mengenai keberagaman pada surat Mazmur ayat 9

Segala bangsa yang Kau jadikan akan datang sujud menyembah di hadapan-Mu, ya Tuhan, dan akan memuliakan nama-Mu. ${ }^{30}$

${ }^{28}$ YIPC, Dokumen Kompilasi, 11-21.

${ }^{29}$ Alquran, 49:13

${ }^{30}$ Injil, Mazmur 86:9. 
Dari konsep keberagaman yang dijelaskan dalam Al-Quran dan Injil dapat ditarik poin penting yaitu: Pertama, Keragaman adalah realitas di sekitar yang tidak bisa dihindari. Kedua, menggambarkan sesuatu tidak sama dengan menilai sesuatu. Menggambarkan itu objektif, sementara menilainya bersifat subjektif. Ketiga, seseorang tidak dapat menempatkan standar mereka pada orang lain. Keempat, hormati keunikan masing-masing individu.

Dengan kata lain, keberagaman dapat disimpulkan sebagai potensi untuk karya bersama. Oleh karena itu, untuk merayakan keberagaman membutuhkan pengakuan yang mendalam terhadap realitas keberagaman tersebut. ${ }^{31}$

\section{Konflik Tanpa Kekerasan}

Konsep konflik tanpa kekerasan dalam nilai perdamaian di dasari pada Alquran surat Fushshilat ayat 34

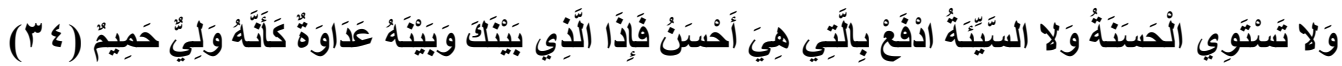

dan tidaklah sama kebaikan dan kejahatan. Tolaklah (kejahatan itu) dengan cara yang lebih baik, Maka tibatiba orang yang antaramu dan antara Dia ada permusuhan seolah-olah telah menjadi teman yang sangat setia. $^{32}$

Serta dalam perpektif kristen, konflik tanpa kekerasan dijelaskan dalam Surat Roma ayat 17-18:

\footnotetext{
"Kejahatan jangan kamu balas dengan kejahatan. Usahakanlah agar kamu melakukan apa yang baik menurut pandangan semua orang. Jika mungkin, yaitu apabila bergantung kepadamu, hiduplah damai dengan semua orang." 33
}

Dalam lingkungan sosial, konflik tidak mungkin dihindari karena setiap individu dalam kelompok pasti memiliki konflik di dalamnya. Namun, itu tergantung pada perspektif individu untuk menangani dan mengelola konflik yang ada sehingga konflik tidak mengarah pada kekerasan khususnya dalam konteks perbedaan ideologis yang dapat mengarah pada ekstremisme. Ada beberapa cara untuk memandang konflik, yaitu: konflik dianggap sebagai sesuatu yang buruk yang harus dihindari atau konflik didasarkan pada asumsi bahwa konflik adalah sesuatu yang tidak dapat dihindari sebagai konsekuensi logis interaksi manusia. Perbedaan dapat menjadi sumber konflik, konflik juga dapat

${ }^{31}$ YIPC, Dokumen Kompilasi, 22-34.

${ }^{32}$ Alquran, 41: 34

${ }^{33}$ Injil, Roma 12: 17-18. 
menyebabkan kekerasan (fisik dan psikologis), kekerasan tidak akan pernah menyelesaikan konflik, tetapi akan mengarah pada kekerasan lain, bahkan lebih parah, dan resolusi konflik tanpa kekerasan adalah respon untuk mengakhir konflik yang ada. Nirkekerasan adalah perjuangan aktif dalam menolak segala bentuk ekstremisme. ${ }^{34}$

Ada beberapa cara efektif untuk menyelesaikan konflik tanpa kekerasan yaitu: mengikhlaskan, berdialog empat mata, dan mencari mediator sebagai orang ketiga.

\section{Berdamai Dengan Lingkungan}

Berdamai dengan lingkungan dapat diartikan sebagai menjaga bumi dari kerusakan yang notabene dilakukan oleh manusia. ${ }^{35}$ Nilai perdamaian ini didasari pada surat al-Rum ayat 41-42:

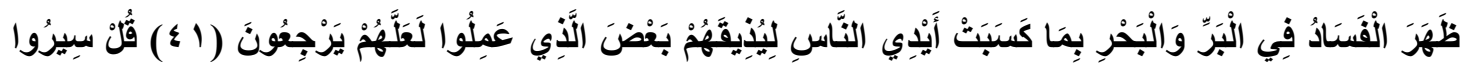

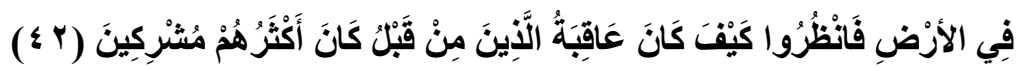

Telah nampak kerusakan di darat dan di laut disebabkan karena perbuatan tangan manusi, supay Allah merasakan kepada mereka sebahagian dari (akibat) perbuatan mereka, agar mereka kembali (ke jalan yang benar). Katakanlah: "Adakanlah perjalanan di muka bumi dan perhatikanlah bagaimana kesudahan orang-orang yang terdahulu. kebanyakan dari mereka itu adalah orang-orang yang mempersekutukan (Allah)." 36

Di dalam Kitab Taurat juga dijelaskan mengenai berdamai dengan lingkungan pada surat Yesaya ayat 3-5

Bumi akan ditanduskan setandus-tandusnya, dan akan dijarah sehabis-habisnya, sebab Tuhanlah yang mengucapkan firman ini. Bumi berkabung dan layu, ya, dunia merana dan layu, langit dan bumi merana bersama. Bumi cemar karena penduduknya, sebab mereka melanggar undang-undang, mengubah ketetapan dan mengingkari perjanjian abadi. ${ }^{37}$

Dari pemaparan pondasi kitab suci diatas, dapat dipahami beberapa poin yaitu: 1) Bumi ini diciptakan dengan keindahan yang luar biasa dengan aneka keragaman hayatinya 2) Manusia adalah konsumen terbesar. Manusia butuh untuk memenuhi kebutuhan jasmaninya. 3) Dikarenakan keserakahan manusia dan mencoba untuk melanggar undangundang Allah, maka kerusakan/ kehancuran alam tak terelakkan. 4) Tugas manusia seharusnya menjaga lingkungan, sebagaimana yang difirmankan oleh Allah dalam Alquran surat Al-Baqarah 2: 30 dan Injil Surat Kejadian 1: 26. 5) Mulai jaga lingkungan dengan

\footnotetext{
${ }^{34}$ YIPC, Dokumen Kompilasi, 35-42.

35Ibid, 43-44.

${ }^{36}$ Alquran, 30:41-42.

${ }^{37}$ Injil (Yesaya 24: 3-5).
} 
cara-cara sederhana, seperti: a) Hemat penggunaan plastik, tisu, listrikb. b) Membuang dan mengolah sampah dengan tepat. c) Tidak menyisakan dan menyia-nyiakan makanan

\section{Berdamai Dengan Allah}

Dalam konsep nilai perdamaian berdamai dengan Allah, Alquran memberikan pondasi dalam surat al-Tahrim ayat 8

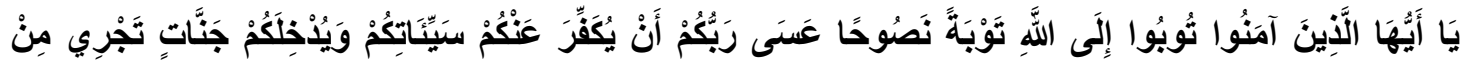

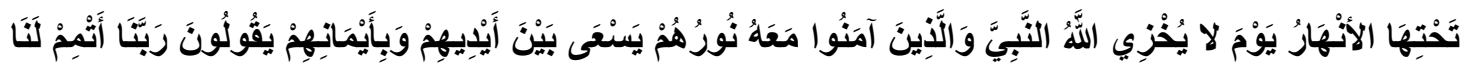

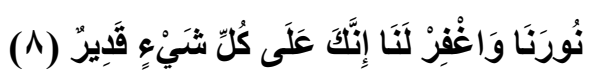

Hai orang-orang yang beriman, bertaubatlah kepada Allah dengan taubatan nasuhaa (taubat yang semurnimurninya). Mudah-mudahan Rabbmu akan menutupi kesalahan-kesalahanmu dan memasukkanmu ke dalam jannah yang mengalir di bawahnya sungai-sungai, pada hari ketika Allah tidak menghinakan Nabi dan orang-orang mukmin yang bersama dia; sedang cahaya mereka memancar di hadapan dan di sebelah kanan mereka, sambil mereka mengatakan: "Ya Rabb Kami, sempurnakanlah bagi Kami cahaya Kami dan ampunilah kami; Sesungguhnya Engkau Maha Kuasa atas segala sesuatu." 38

Dan di dalam Injil dijelaskan dalam Surat Korintus ayat 18-20

"Kami adalah duta-duta bagi Al Masih. Dengan perantaraan kami, Allah menyampaikan apa yang dikehendakiNya. Jadi, demi Al Masih kami meminta kepadamu: Berdamailah dengan Allah!"39

Konsep berdamai dengan Allah dari kedua pondasi diatas dapat dipahami beberapa poin sebagai berikut: ${ }^{40}$ 1) Berdamai dengan Allah menjadi upaya untuk kembali pada jalan kebaikan dan menggugurkan dosa-dosa yang diperbuat oleh manusia. 2) Allah pemilik seluruh kehidupan dan alam semesta dan pada hakikatnya hidup adalah tentang Allah. 3) Berdamai dengan Allah menjadi wujud titik balik untuk bisa menjadi hamba dan pelayanNya- Dosa merupakan jurang pemisah yang membuat manusia terhalang dari rahmatNya. Sehingga tidak ada jalan lain kecuali kembali ke jalan yang benar dan menjalankan apa yang menjadi kehendak-Nya, Do for God, do with God, do by God, Berdamai dengan Tuhan merupakan inti dan awal untuk dapat berdamai dengan diri sendiri, sesama, dan lingkungan”. 4) Meminta Maaf dan Memaafkan

\footnotetext{
${ }^{38}$ Alquran, 66:8.

${ }^{39}$ Injil, Korintus 5: 18-20.

${ }^{40}$ YIPC, Dokumen Kompilasi, 52-58.
} 
Konsep nilai perdamaian yang terakhir adalah meminta maaf dan memaafkan. ${ }^{41}$ Konsep ini tertulis dalam Alquran surat al-Shuara ayat 40

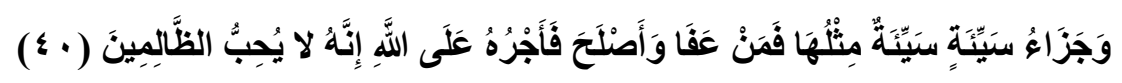

dan Balasan suatu kejahatan adalah kejahatan yang serupa, Maka barang siapa memaafkan dan berbuat baik Maka pahalanya atas (tanggungan) Allah. Sesungguhnya Dia tidak menyukai orang-orang yang zalim. ${ }^{42}$

Di dalam injil dijelaskan juga mengenai anjuran memafkan dan meminta maaf seperti yang ditulis dalam surat Kolose ayat 13

Sabarlah kamu seorang terhadap yang lain, dan ampunilah seorang akan yang lain apabila yang seorang menaruh dendam terhadap yang lain, sama seperti Tuhan telah mengampuni kamu, kamu perbuat jugalah demikian. ${ }^{43}$

Dari pondasi kedua sumber hukum agama diatas, dapat diambil beberapa poin pemahaman mengenai memaafkan dan meminta maaf: 1) Setiap manusia pernah berbuat salah. Tuhan memerintahkan kita untuk meminta maaf dan memaafkan. 2) Tidak ada damai yang sejati tanpa rekonsiliasi. Rekonsiliasi memerlukan kedua pihak untuk saling meminta maaf dan memaafkan. 3) Tips meminta maaf antara lain: selalu berdoa dulu, akui kesalahan, minta maaf, siap menerima konsekuensi, mengubah tindakan menjadi lebih baik. 4) Kesalahpahaman dalam memaafkan antara lain: memaafkan jika sudah enak hati, memaafkan sama dengan melupakan, memaafkan adalah jaminan bahwa kita tidak tersakiti lagi, memaafkan sama dengan mengatakan "tidak masalah"

\section{Manifestasi Program YIPC Dalam Menyuarakan Narasi Kontra Radikal}

Ada beberapa Program YIPC yang mendasari proses penyebaran narasi kontraradikalisme pada pemuda. Program ini berfungsi sebagai strategi YIPC dalam mewujudkan upaya-upaya perdamaian. Pertama, Student Interfaith Peace Camp (SIPC). SIPC Berkonsentrasi pada pendidikan perdamaian untuk mereduksi ideologi radikalisme. Konsep program SIPC adalah kombinasi dari pendidikan perdamaian dan dialog antaragama yang dibingkai dalam bentuk pelatihan pada pemuda. Pendidikan perdamaian yang digunakan dalam program ini adalah hasil adopsi dari konsep perdamaian milik NGO Peace Generation dan Campus Movement yang kemudian dielaborasi dan dimodifikasi sesuai dengan kebutuhan konteks visi dan misi

${ }^{41}$ YIPC, Dokumen Kompilasi, 61-62.

${ }^{42}$ Alquran, 26:40.

${ }^{43}$ Injill, Kolose 3: 13 
dari YIPC. ${ }^{44}$ Berawal dari tahun 2012 SIPC pertama dilakukan di Yogyakarta. Hingga tahun 2018, sudah ada delapan regional yang melakukan kegiatan SIPC setiap semester, yaitu Medan, Bandung, Yogyakarta, Surabaya, Malang Jakarta, Salatiga, dan secara nasional. Secara total, ada 2.277 peserta yang telah melakukan pelatihan pendidikan perdamaian. Artinya, YIPC telah menarasikan kontra-radikalisme sesuai dengan salah satu pendekatan yang dilakukan oleh BNPT, yaitu reedukasi untuk mengurangi pemahaman radikalisme yang terjadi baik di kalangan Muslim maupun Kristen. Program SIPC dimanifestasikan untuk mengurangi ideologi radikal dari masing-masing agama melalui beberapa tahap yang pada dasarnya mengajarkan konsep nilai-nilai perdamaian yang telah dirumuskan oleh YIPC. Pertama, untuk membuktikan bahwa ada benih radikal dan menganggap kelompok itu sebagai kelompok eksklusif, peserta SIPC baik Muslim maupun Kristen, diberikan kertas untuk menulis prasangka terhadap masing-masing agama secara dogma dan praktik. Dari setiap SIPC yang telah diadakan, hampir 100\% tidak ada perbedaan antara prasangka yang ditulis oleh orang Kristen dan Muslim. Misalnya, umat Islam memiliki prasangka terhadap agama Kristen di Dogma seperti: Orang Kristen memiliki tiga Tuhan (Yesus, Allah, dan Roh Kudus), Isa as (Yesus) adalah anak Allah, Isa as (Yesus) disalibkan bukan sebagai pengorbanan, tetapi Yudas Iskariot yang berkhianat kepada Murid-murid Yesus yang menggantikan Yesus untuk disalibkan, Kristen adalah agama kafir, dan Kristen bukanlah agama yang benar. Dalam praktiknya, umat Islam berprasangka, seperti: Orang Kristen makan daging babi, doa-doa mereka hanya bernyanyi, dan orang Kristen merasa terganggu oleh suara adzan. Sebaliknya, orang Kristen memiliki prasangka terhadap Muslim dalam dogma seperti: menganggap orang di luar Muslim sebagai orang kafir, tidak boleh menggambar Nabi, dan membiarkan perceraian. Dalam praktiknya, orang Kristen berprasangka terhadap umat Islam seperti poligami, kejahatan teroris, permohonan doa yang menggunakan pengeras suara, dan perbedaan golongan seperti Sunni, Syiah, dan Ahmadiyah.

Dari bukti inilah dasar dilakukannya program SIPC karena memang kedua agama ini benar-benar berseteru dan perlu duduk bersama untuk mendamaikan prasangka antar satu sama lain. Karena munculnya benih-benih radikalisme dimulai dengan prasangka buruk tanpa akhir yang diperkuat oleh pemahaman yang tidak tepat terhadap ayat-ayat suci yang pada akhirnya menyebabkan kebencian di antara kelompok tersebut dan saling menganggap bahwa kelompok itu merupakan kelompok eksklusif.

${ }^{44}$ Faiz Miftahul Huda, Wawancara, Sidoarjo. 23 Maret 2019. 
Setelah masing-masing prasangka dituangkan maka, secara jelas dan konkrit bahwa ada poin-poin yang harus diklarifikasi dalam sesi rekonsiliasi. Kesalahpahaman dan prasangka yang tertulis disebabkan tidak adanya kesempatan untuk mengenal secara langsung melalui sumbernya dan hanya menerima dari berita-berita yang secara jelas memprovokasi hingga akhirnya menimbulkan benih-benih ideologi radikal.

Tahap selanjutnya adalah sesi pelatihan untuk mengajarkan nilai-nilai perdamaian yang diajarkan dalam YIPC. Konteks nilai perdamaian sendiri sebenarnya bila dijadikan lebih rapat, maka terdapat tiga kategori yaitu memperbaiki hubungan dengan Allah (bablum min Allah), memperbaiki hubungan dengan manusia (bablum min al-nass), dan memperbaiki hubungan dengan alam (hablum min al-'aläm), yang kemudian kategori ini dinarasikan sebagai empat belas butir nilai perdamaian yang diringkas menjadi tujuh yaitu menerima diri, mengatasi prasangka, merayakan keberagaman, konflik tanpa kekerasan, berdamai dengan lingkungan, berdamai dengan Allah, serta meminta maaf dan memaafkan. Diakhir program, secara keseluruhan prasangka dogma dan praktik antar sesama telah dikonfirmasi dan diklarifikasi bagaimana sebetulnya pernyataan tersebut dengan menggunakan kacamata nilai perdamaian yang telah disampaikan sebelumnya.

Kedua, follow up anggota di setiap regional. Follow up ini dilakukan dengan cara mengajak beberapa non-anggota untuk melakukan diskusi tematik dan melakukan kajian SR (Scriptural Reasoning) $^{45}$.

Diskusi yang dilakukan dalam rangka untuk membangun kebersamaan atas isu-isu kemanusiaan yang dibingkai dengan dialog lintas agama. Seperti contoh yang baru dilakukan yakni membahas istilah kafir dalam paradigma Islam dan Kristen akibat munculnya pro dan kontra atas penghapusan istilah kafir. Dalam hal ini antara Muslim dan Kristen membahas mengenai kafir perspektif agama masing-masing yang kemudian ditemukan titik temu dalam konteks perdamaian yakni istilah kafir sangat tidak tepat apabila dipakai untuk menjatuhkan dan menjustifikasi orang non-muslim secara langsung karena memang istilah kafir digunakan sebagai konteks akidah bukan sebagai konteks labelisasi agama karena dalam istilah Kristen juga digunakan istilah yang hampir sama untuk menandakan akidah non-Kristen yakni dengan istilah domba yang tersesat. Dalam diskusi ini ditemukan kebersamaan dan sikap saling menerima yang di dukung juga dari pemahaman antar kitab suci masing-masing. Jadi bukan hanya mendapatkan prasangka dari isu yang berkembang di masyarakat, melainkan melakukan

${ }^{45}$ Scriptural Reasoning merupakan kajian antara Alquran dan Injil yang mengupas satu tema tertentu yang tertulis di dalam masing-masing kitab untuk ditemukan titik temu dan mendialogkan menurut perspektif masingmasing. 
kajian secara mendalam mengenai makna kafir sehingga dapat saling menerima dan memahami antar satu sama lain dalam perbedaan agama. Manifestasi dari program SR dan diskusi tematik yang dilakukan yakni dengan memahami konteks kebersamaan antar agama walaupun dengan sumber kitab suci yang berbeda dan bahkan membahas isu yang sangat sensitif untuk menemukan titik temu agar saling dapat memahami. Dengan memahami sumber ajaran dari kedua agama tersebut, maka dapat ditemukan suatu titik temu yang menjadi pondasi melakukan perdamaian.

Ketiga, penyebaran nilai-nilai dalam dokumen a common word. Manifestasi dalam program ini adalah fasilitator bekerja sama dengan beberapa kampus atau komunitas untuk menyampaikan bagaimana dokumen a common word dapat terbentuk dan bagaimana esensinya dalam menyatukan antara Islam dan Kristen dalam konteks kebersamaan dan perdamaian, bukan dalam rangka untuk menyatukan akidah secara sinkretisme.

Konsep dalam a common word sejalan dengan konsep piagam madinah yang esensinya untuk hidup bersama tanpa kekerasan antar pemeluk agama. Inti utama dari konsep a common word yakni menjelaskan adanya ketersinambungan antara Islam dan Kristen dalam memahami hubungan dengan Tuhannya dan hubungan antara manusia. Bahwa, sangat tidak mungkin terjadi apabila seseorang mengaku mencintai Tuhannya tetapi tidak mencintai sesamanya yang notabene merupakan ciptaan dari Tuhan. Oleh karena itu, konsep cinta terhadap Tuhan dan cinta terhadap sesama merupakan dua sisi koin yang tidak dapat terpisahkan. Dari konsep inilah, manifestasi dari a common word dilakukan dan disebarkan secara meluas baik secara bekerja sama dengan berbagai elemen maupun secara tulisan yang diterbitkan dalam majalah Peace News.

Keempat, melakukan aksi sosial. Program selanjutnya yakni melakukan kegiatan sosial seperti kampanye damai yang pernah dilakukan di Taman Bungkul dengan mengundang elemen organisasi pemuda se-Jawa Timur dalam rangka memperingati hari toleransi internasional, bakti sosial kepada pengungsi syi'ah di Sidoarjo, mengunjungi rumah ibadah agama lain dengan tujuan mendapat penjelasan secara utuh mengenai prasangka-prasangka yang tersebar di masyarakat dalam rangka memperingati World Interfaith Harmony Week (Harmoni Pekan Lintas Agama) yang notabene merupakan agenda dari PBB pada bulan Februari, dan menjadi salah satu pelopor dalam kegiatan aksi empati di Tugu Pahlawan Surabaya terhadap kasus pengeboman di tiga gereja di Surabaya.

Tentunya dalam melakukan kegiatan ini, YIPC mengundang pemuda yang berbeda agama untuk bersinergi dan mengesampingkan ekslusifitas agama dengan tujuan melakukan 
aksi sosial yang bermanfaat bagi orang lain. Dari kegiatan ini didapatkan hasil bahwa bila pemuda Kristen dan Muslim disatukan dalam wadah aksi sosial, maka mereka mengesampingkan urusan prasangka terhadap sesamanya demi mencapai tujuan bersama. Manifestasi dari program ini yakni bertujuan untuk mensinergikan antara Kristen dan Muslim untuk bekerja sama tanpa melihat background agama demi memberikan manfaat kepada orang lain.

Hasil dari strategi manifestasi program YIPC menghasilkan beberapa output. Pertama, dalam program SIPC menghasilkan output pemuda yang telah latih dalam sesi pelatihan SIPC menjadi agent of peace untuk menyebarkan perdamaian dan mengesampingkan diferensiasi dan bias yang dapat menimbulkan prasangka negatif dan berideologi radikal. Hal ini dibuktikan dari beberapa testimoni peserta setelah mengikuti pelatihan dalam program SIPC sebagai berikut:

“.........Bertemu kawan dengan latar belakang agama, suku, etnis dan negara yang berbeda tentu menjadi sesuatu yang menarik. Kita bisa belajar bersama untuk saling menerima, respect terhadap sesama serta mengklarifikasi terhadap prasangka-prasangka secara langsung......" 46

“..........Sebelum gabung di YIPC, saya sangat ekslusif. Sehingga, banyak sekali prasangka-prasangka yang saya simpan kepada teman-teman yang berbeda agama. Apalagi karena saya hidup di Pesantren dan kuliah di Universitas Islam, jadi untuk berinteraksi dengan orang yang berbedaitu sangat terbatas. Juga, sebelum bergabung dengan YIPC, saya belum pernah menyentuh, membaca dan memahami kitab suci agama lain, dan saya tdak memiliki teman yang berbeda agama. Yang menarik dari kegiatan YIPC yg pernah saya ikut adalah sebuah kebersamaan. Saya akui bahwa YIPC mampu membuat suasana kebersamaan itu terasa indah meskipun di dalamnya terdapat banyak perbedaan, baik itu di kegiatan Peace Camp, Natonal Conference, Training for Facilitator, dan World Interfaith Harmony Week (WIHW) yang pernah saya ikut ."47

Tidak hanya berhenti dalam testimoni saja, melainkan beberapa peserta yang telah mengikuti program SIPC turut melakukan aksi perdamaian dengan cara turun ke jalan maupun menjadi kontributor untuk menyebarkan narasi kontra-radikalisme melalui tulisan.

Kedua, hasil output dari program diskusi tematik dan SR (Scriptural Reasoning) membuka pemikiran orang lain atas dialog-dialog sensitif atas nama kedua agama yakni Islam dan Kristen untuk saling memahami dan mencari titik temu untuk menghilangkan prasangka atas kedua agama serta memberikan contoh dialog lintas agama tanpa saling mendebat dan menyalahkan antar satu sama lain, tetapi saling mengerti dan memahami antar satu sama lain walaupun yang diangkat adalah tema yang cukup sensitif.

\footnotetext{
"46Amiril Ardiansyah, "Testimoni”, YIPC Newsletter Peace News, (Oktober 2017): 24, http://peacenews.yipci.org/peacenews-edisi-oktober/.

"77Anisa, "Testimoni", YIPC Newsletter Peace News, (Februari 2018): 23, http:/ / peacenews.yipci.org/peacenews-februari-2018-eksklusivisme-perlukah/.
} 
Ketiga, output dari penyebaran esensi a common word di berbagai kampus dan komunitas menjelaskan secara luas bahwa dalam kitab suci Kristen dan Islam terdapat beberapa titik temu yang merupakan alasan untuk tidak mempunyai alasan saling berprasangka negatif atas dasar agama.

Keempat, sinergitas antar pemuda lintas agama dalam aksi sosial memunculkan output untuk bekerja sama dalam perbedaan demi mencapai tujuan bersama yakni memberikan manfaat kepada orang lain tanpa harus pandang agama dan ras.

Dari beberapa output program YIPC khususnya program SIPC maka dapat ditarik suatu pemahaman bahwa pendidikan perdamaian dan interfaith dialogue yang dibingkai dengan konsep 14 nilai perdamaian dalam suatu training, diskusi, dan aksi nyata dapat mereduksi ideologi radikalisme baik dalam Kristen maupun Islam khususnya di lingkungan pemuda.

\section{Peran YIPC Dalam Membangun Narasi Kontra Radikal}

Berbicara mengenai peran sama dengan berbicara mengenai fungsionalitas sebuah institusi atau personal yang dijadikan sebagai aktor dengan narasi-narasi skenario tertentu. Meminjam konsep yang dikemukakan oleh BJ. Biddle bahwasannya peran adalah serangkaian triadik yang saling berhubungan dua arah antara pola dan karakteristik sosial, identitas perilaku sosial dan skrip atau job description yang menjadi landasan untuk melakukan peran. ${ }^{48}$

Dalam penelitian ini setidaknya ada tiga aspek yang harus dipenuhi oleh YIPC untuk memposisikan peran yang harus diambil dalam upaya menarasikan kontra radikalisme agama. Pertama, pola dan karakter dari YIPC. Kedua, identitas dari YIPC. Ketiga, skenario yang diambil oleh YIPC. Sebelum beberbicara mengenai pengambilan peran YIPC dalam upaya menyebarkan narasi kontra-rradikalisme agama, maka harus dipahami terlebih dahulu bagaimana YIPC mengambil tempat posisi sosial dari bagian konsep konsensus Indonesia. Merujuk kepada Undang-Undang Nomor 5 Tahun 2018 salah satu proses deradikalisasi yang dilakukan oleh pemerintah adalah melakukan reedukasi terhadap orang atau kelompok yang terpapar paham radikal. ${ }^{49}$ Jadi penempatan posisi sosial YIPC terhadap konsensus yang ada yakni menjadi wadah edukasi pemaparan narasi kontra radikalisme.

Kedua, yang harus diperhatikan yakni konformitas yang dilakukan oleh YIPC terhadap proses deradikalisasi yang telah dilakukan oleh Pemerintah. Merujuk kepada penelitian yang dilakukan oleh Badan Intelijen Negara pada tahun 2017 bahwasannya tercatat sebanyak 39

${ }^{48}$ Biddle, "Recent Developments in Role Theory," 68.

${ }^{49}$ UU No. 52018 Tentang Perubahan Atas Undang-Undang Nomor 152003 Tentang Penetapan Peraturan Pemerintah Pengganti Undang-Undang Nomor 1 Tahun 2002 Tentang Pemberantasan Tindak Pidana Terorisme Menjadi Undang-Undang. 
persen mahasiswa dari sejumlah perguruan tinggi terpapar radikalisme. ${ }^{50}$ Namun di tahun 2018, Kementrian Riset dan Teknologi Pendidikan Tinggi dan Badan Intelijen Negara memberikan keterangan bahwa gerakan dan penyebaran radikalisme di perguruan tinggi dan di masjid pemerintahan turun. ${ }^{51}$ Tren radikalisme dan intoleransi kembali naik di penghujung tahun 2018 dengan merujuk kepada survey yang dilakukan oleh Burhanuddin Muhtadi ${ }^{52}$ akibat dari gerakan 212. Di tahun 2016 tingkat intoleransi berada diangka 13,7 persen dan ditahun 2018 pra dan pasca gerakan 212 tingkat intoleransi di Indonesia menjadi 31 persen. Selain tingkat intoleransi yang meningkat, keinginan melakukan aksi radikalisme juga meningkat. Pada tahun 2016 masih menunjukkan angka sebesar 7,7 persen. Namun di tahun 2018 naik dan menunjukkan angka 11 persen. Dari survey ini diketahui bahwa aksi 212 adalah awal kembali naiknya tren intoleransi dan radikalisme yang sebelumnya turun. ${ }^{53}$

Dengan mengabaikan angka dari survei yang dilakukan, bila mengacu kepada kacamata fenomenologi terjadi fenomena yang muncul atas pembubaran Hizbut Tahrir. Maraknya respon terhadap Pemerintah yang dikatakan sebagai anti ulama, tidak diterimanya seseorang dalam suatu lingkungan masyarakat karena berbeda agama, hingga larangan menyolatkan mayat karena berbeda pandangan politik. Hal ini yang menjadikan YIPC mengambil sikap konformitas serta harus mengambil bagian dalam menarasikan kontra-radikalisme agama yang dikarenakan ketidaksesuaian antara ekspektasi dan perilaku kontra radikalisme dan deradikalisasi yang dilakukan.

Ketiga mengenai konflik peran yakni ketidaksesuaian antara realitas dan perilaku suatu aktor untuk menyelesaikan masalah hingga akhirnya mencari alternatif penyelesaian masalah. Dalam kasus ini, YIPC sangat tidak mampu untuk menjadikan proses deradikalisasi sama dengan apa yang dilakukan pemerintah dengan melakukan empat tahapan yakni identifikasi, rehabilitasi, reedukasi, dan reintegrasi-resosialiasi. Namun, alternatif pencapaian proses deradikalisasi yang dapat dilakukan oleh YIPC adalah melalui pendekatan reedukasi mengenai membangun perdamaian. Merujuk pada wawancara kepada Joshua Bernard, Head Fasilitator Surabaya mengatakan bahwasannya konsentrasi YIPC dalam upaya menarasikan kontra-

\footnotetext{
50Wishnugroho Akbar, "BIN Ungkap 39 Persen Mahasiswa Terpapar Radikalisme," diakses 04 April 2019, https://www.cnnindonesia.com/nasional/20180429023027-20-294442/bin-ungkap-39-persen-mahasiswaterpapar-radikalisme.

${ }^{51}$ Wijaya Kusuma, "Menristek Dikti: Gerakan radikalisme di Perguruan Tinggi Relatif Turun," www.regional.kompas.com; Ninis Chairunnisa, "BIN: Penyebaran Radikalisme di Masjid Pemerintahan Turun," diakses 04 April 2019, https://nasional.tempo.co/read/1148211/bin-penyebaran-radikalisme-di-masjidpemerintahan-menurun.

${ }^{52}$ Burhannuddin Muhtadi adalah peneliti Indikator Politik Indonesia.

${ }^{53 R i z k i ~ R a m a d h a n, ~ " S u r v e i: ~ A k s i ~} 212$ Tingkatkan Tren Intoleransi dan Radikalisme," diakses 04 April 2019, https://tirto.id/survei-aksi-212-tingkatkan-tren-intoleransi-dan-radikalisme-daCA.
} 
radikalisme agama berpusat kepada dua aspek yaitu Peace Building yang dilandasi oleh Interfaith Dialogue. ${ }^{54}$ Jadi alternatif penyelesaian masalah deradikalisasi yang dilakukan oleh YIPC adalah fokus terhadap reedukasi.

Keempat pengambilan peran. Berbicara mengenai pengambilan peran maka harus juga berbicara mengenai program YIPC berserta manifestasinya. Hal ini dimaksudkan bahwa program dan manifestasi YIPC adalah landasan yang dijadikan skenario dan perilaku atas peran yang diambil oleh YIPC. Ada empat skenario inti yang dimiliki oleh YIPC dalam upaya menarasikan kontra-radikalisme agama. Pertama program SIPC yang merupakan pelatihan pemuda lintas agama untuk terlibat aktif di dalamnya untuk menjadikan pemuda sebagai kader perdamaian dalam menyebarkan 14 nilai perdamaian. Dalam skenario ini, YIPC bertugas sebagai wadah untuk memfasilitasi pemuda lintas agama mempelajari 14 nilai perdamaian dan melakukan dialog lintas agama dengan tujuan mengklarifikasi prasangka yang merupakan akar dari konflik atas nama agama. Mengutip dari penyataan Neni, Head Fasilitator Malang mengemukakan bahwa YIPC juga menjembatani pemuda Muslim dan Kristen untuk berdialog dan saling mengkalrifikasi prasangka yang selama ini telah mendarah daging. ${ }^{55}$

Kedua, diskusi tematik dan pengkajian SR (Scriptural Reasoning). Dalam skenario ini, YIPC bertugas sebagai wadah secara umum dan pemantik dalam melakukan dialog lintas agama. Hasil dari tugas yang dilakukan oleh YIPC diketahui bahwa dalam tema yang sensitif antar kedua agama dapat dimaknai untuk saling memahami dan menerima.

Ketiga, penyampaian dan penyebaran a common word yang berintegrasi dengan komunitas dan perguruan tinggi. Dalam skenario ini, YIPC mengirimkan beberapa fasilitator untuk menyampaikan konsep a common word sebagai landasan narasi kontra-radikal dalam bentuk edukasi. Penyelarasan hubungan antara Tuhan, manusia, dan alam merupakan pondasi dan cara berpikir kader perdamaian untuk menyebarkan nilai perdamaian.

Keempat, kampanye perdamaian yang melibatkan individu diluar YIPC dan berintegrasi dengan beberapa komunitas. Dalam skenario ini, YIPC bertugas secara institusi sebagai organisasi yang berkolaborasi dengan komunitas lain untuk melakukan aksi sosial. Dalam hal ini ditemukan bahwa YIPC menjadi pelopor dan mengundang komunitas lain untuk bergabung dengan berbagai program kemanusiaan yang digagas oleh YIPC.

Dari keempat skenario yang dijalankan oleh YIPC dapat dijadikan pemaparan bahwa peran yang diambil oleh YIPC adalah sebagai wadah untuk memfasilitasi pelatihan nilai

54Joshua Bernard Kristian, Wawancara, Surabaya. 12 Februari 2019.

55Neni Adyamuka, Wawancara, Pasuruan. 24 Maret 2019. 
perdamaian, memfasilitasi dan pemantik dalam dialog lintas agama, penyebaran nilai-nilai kemanusiaan yang ada di dalam a common word, dan kolaborator antar berbagai komunitas dalam melakukan gerakan sosial anti radikalisme dan intoleransi.

Sebelum menentukan peran apa yang diambil oleh YIPC dalam upaya menarasikan kontra-radikalisme agama, dari skenario-skenario yang ada diproses melalui konsep triadik yang dicetuskan oleh Biddle. Pertama, pola dan karakteristik perilaku sosial. Kedua, bagianbagian atau identitas yang diasumsikan oleh partisipan sosial. Ketiga, skrip atau ekspetasi perilaku yang dipahami oleh semua pihak dan dipatuhi oleh aktor yang berperan. ${ }^{56}$ Pola dan karakteristik yang dilakukan oleh YIPC adalah organisasi yang memfokuskan diri kepada peace building dan interfaith dialogue. Identitas YIPC adalah sesuai dengan mission statement di dalam anggaran dasar dan anggaran rumah tangga yaitu building peace generation through young peacemakers yang artinya membangun generasi damai melalui kader muda damai. Skrip atau skenario dari YIPC adalah sebagai wadah untuk memfasilitasi pelatihan nilai perdamaian, memfasilitasi dan pemantik dalam dialog lintas agama, penyebaran nilai-nilai kemanusiaan yang ada di dalam $a$ common word, dan kolaborator antar berbagai komunitas dalam melakukan gerakan sosial anti radikalisme dan intoleransi. Dari sinergi konsep triadik peran yang dikemukakan oleh Biddle, dapat dilihat bahwa peran YIPC dalam menarasikan kontra-radikalisme agama adalah sebagai wadah dan fasilitator bagi pemuda lintas iman yang berkonsentrasi pada konsep pendidikan perdamaian dan dialog antaragama yang berdasarkan pada kitab suci untuk membangun perdamaian melalui kader perdamaian dengan menyebarkan empat belas nilai dasar perdamaian untuk mengurangi ideologi radikalisme dan intoleransi. Berdasarkan peran yang melekat dalam diri YIPC, ada sinergi untuk membantu pemerintah dalam program deradikalisasi melalui pendekatan reedukasi.

\section{KESIMPULAN}

Program yang dirumuskan oleh YIPC dalam menyebarkan narasi kontra-radikalisme agama yaitu: student interfaith peace camp (SIPC), kajian tematik dan kajian scriptural reasoning, penyebaran nilai a common word yang bekerja sama dengan berbagai institusi dan organisasi, dan kegiatan aksi sosial beserta kampanye damai. Program YIPC diejawantahkan dengan cara melakukan reedukasi dengan menyampaikan nilai-nilai perdamaian dalam program SIPC yang dibingkai dengan training pemuda lintas agama, melakukan diskusi lintas agama agar saling menemukan titik temu untuk menghargai dan menghormati satu sama lain, melakukan kerjasama dengan instansi dan organisasi untuk saling berdiskusi dan memahami nilai yang

\footnotetext{
56Biddle, "Recent Developments in Role Theory," 68.
} 
terkandung dalam dokumen a common word, dan melakukan community building dengan cara mensinergikan YIPC untuk berkolaborasi dengan pemuda dan organisasi lain dalam melaksanakan kegiatan sosial yang bertujuan untuk mempererat persaudaraan walaupun dalam agama, ras, dan suku yang berbeda. Berdasarkan hasil dari program yang telah dilaksanakan, YIPC mengambil peran sebagai wadah dan fasilitator pemuda antaragama yang berkonsentrasi pada konsep pendidikan perdamaian dan dialog antaragama yang berdasarkan kitab suci untuk membangun perdamaian melalui peacemaker dengan menyebarkan nilai-nilai dasar perdamaian yang berkontribusi kepada negara untuk mengurangi ideologi radikalisme dan intoleransi.

\section{REFERENSI}

Amiril Ardiansyah. "Testimoni”". YIPC Newsletter Peace News. (Oktober 2017): 24. http://peacenews.yipci.org/peacenews-edisi-oktober/

Anisa. "Testimoni”. YIPC Newsletter Peace News. (Februari 2018): 23. http://peacenews.yipci.org/peacenews-februari-2018-eksklusivisme-perlukah/

Asosiasi Penyedia Jasa Internet Indonesia. "Hasil Survey Penetrasi dan Perilaku Pengguna Internet Indonesia Tahun 2017.” Diakses 11 Juni 2020. https:/ /apjii.or.id/survei

Ahyar, Muzayyin. "Membaca Gerakan Islam Radikal Dan Deradikalisasi Gerakan Islam.” Walisongo: Jurnal Penelitian Sosial Keagamaan 23, no. 1 (15 Juni 2015): 1-26. https://doi.org/10.21580/ws.23.1.220.

Arifin, Syamsul. "Membendung Arus Radikalisasi di Indonesia." Islamica: Jurnal Studi Keislaman 8, no. 2 (1 Maret 2014): 392-420. https://doi.org/10.15642/islamica.2014.8.2.392420.

Azman, Azman. "Gerakan Dan Pemikiran Hizbut Tahrir Indonesia." Al Daulah : Jurnal Hukum Pidana Dan Ketatanegaraan 7, no. 1 (16 Juli 2018): 99-113. https://doi.org/10.24252/ad.v7i1.5329.

B J Biddle, "Recent Developments in Role Theory," t.t., 68. J Biddle, "Recent Developments in Role Theory," t.t., 68.

Booklet YIPC Seri 1. Mengenal Young Interfaith Peacemaker Community Indonesia (YIPC). 2

Faiz Miftahul Huda. Wawancara. Sidoarjo. 23 Maret 2019.

Hadi, Amirul, dan H. Haryono. Metodologi Penelitian Pendidikan. Bandung: Pustaka Setia. 1998. Jonathan, Andreas, Paulus Widjaja, dan Fatimah Husein. "Fostering Religious Exclusivism and Political Pluralism In Indonesia Through Interefaith-Based Student Community." KnE Social Sciences 3. no. 5 (Mei 2018): 68. https://doi.org/10.18502/kss.v3i5.2325 
Kontribusi Young Interfaith Peacemaker Community (YIPC) Dalam Menyebarkan Narasi Kontra Radikalisme

Joshua Bernard Kristian. Wawancara. Surabaya. 12 Februari 2019.

Muthohirin, Nafi'. "Radikalisme Islam dan Pergerakannya di Media Sosial.” Jurnal Ilmu-Imu Keislaman Afkearuna 11, no. 2 (Desember 2015): 250-251. https://doi.org/10.18196/aiijis.2015.0050.240-259.

Nawawi, Hadari. Metodologi penelitian Bidang Sosial. Yogyakarta: Gajah Mada Universy press. 2001.

Neni Adyamuka. Wawancara. Pasuruan. 24 Maret 2019.

Qohar, Abdul, dan Kiki Muhammad Hakiki. "Eksistensi Gerakan Ideologi Transnasional HTI Sebelum dan Sesudah Dibubarkan.” Jurnal Kalam 11, no. 2 (Desember 2017): 388. https://doi.org/10.24042/klm.v11i2.1403.

Rizki Ramadhan. "Survei: Aksi 212 Tingkatkan Tren Intoleransi dan Radikalisme." diakses 04 April 2019. https://tirto.id/survei-aksi-212-tingkatkan-tren-intoleransi-danradikalisme-daCA.

Siswantoro. Metode Penelitian Sastra: Analisis Psikologis. Surakarta: Sebelas Maret University Press. 2004.

UU No. 52018 Tentang Perubahan Atas Undang-Undang Nomor 152003 Tentang Penetapan Peraturan Pemerintah Pengganti Undang-Undang Nomor 1 Tahun 2002 Tentang Pemberantasan Tindak Pidana Terorisme Menjadi Undang-Undang

UU No. 52018.

Wijaya Kusuma. "Menristek Dikti: Gerakan radikalisme di Perguruan Tinggi Relatif Turun." www.regional.kompas.com; Ninis Chairunnisa. "BIN: Penyebaran Radikalisme di Masjid Pemerintahan Turun.” diakses 04 April 2019. https://nasional.tempo.co/read/1148211/bin-penyebaran-radikalisme-di-masjidpemerintahan-menurun.

Wishnugroho Akbar. "BIN Ungkap 39 Persen Mahasiswa Terpapar Radikalisme.” diakses 04 April 2019. https://www.cnnindonesia.com/nasional/20180429023027-20294442/bin-ungkap-39-persen-mahasiswa-terpapar-radikalisme.

YIPC. Dokumen Kompilasi Modul Pendidikan Perdamaian YIPC Indonesia. 2018. 3.

Zada, Khamami. "Radikalisme Di Jantung Pendidikan Islam.” EDUKASI: Jurnal Penelitian Pendidikan Agama Dan Keagamaan 7, no. 4 (15 Mei 2017). https://doi.org/10.32729/edukasi.v7i4.256. 